\title{
PEMBERDAYAAN GURU DI PEDESAAN SEBAGAI SOCIAL CAPITAL PEMBANGUNAN MELALUI FASILITASI PENDIDIKAN BERBASIS KEPEMIMPINAN TRANSFORMASIONAL DAN KOMUNITAS BELAJAR GURU
}

\author{
Adi Suryani \\ UPT PMK Sosial Humaniora, Institut Teknologi Sepuluh Nopember \\ adisuryani.rahman@gmail.com
}

\begin{abstract}
ABSTRAK
Prinsip pembangunan berkeadilan sosial mengindikasikan pentingnya dilaksanakannya pembangunan secara menyeluruh, baik di area perkotaan ataupun daerah pedesaan. Area pedesaan seringkali tertinggal di bidang pendidikan dan pembangunan dikarenakan faktor geografis yang seringkali menghambat masuknya fasilitas dan modernisasi ke area pedesaan. Salah satu pembangunan yang seharusnya mendapat perhatian adalah perkembangan pendidikan di pedesaan. Seringkali siswa di desa tertinggal dalam hal pendidikan dibandingkan dengan siswa di perkotaan. Hal ini dikhawatirkan menimbulkan kesenjangan pendidikan yang dapat menghambat pembangunan. Salah satu cara mengatasinya adalah dengan mengembangkan profesionalisme guru di area pedesaan yang pada akhirnya diharapkan dapat meningkatkan prestasi/kualitas pendidikan siswa di desa. Beberapa metode yang dapat dilaksanakan adalah dengan membentuk komunitas belajar guru sebagai sarana dan media guru untuk bersama-sama belajar dalam struktur komunitas yang lebih bersifat horizontal dan diadaptasikan dalam konteks sosial dan budaya area pedesaan yang bersifat kolektif. Komunitas belajar ini diharapkan lebih efektif untuk mengembangkan kualitas pendidikan dan pengetahuan guru karena lebih bersifat komunitas berkala serta menstimulasi diskusi dan kegiatan kegiatan akademis yang didasarkan pada isu-isu pendidikan yang kekinian dan sesuai dengan konteks sosial dan budaya. Metode yang kedua yaitu dengan melalui pembentukan kepemimpinan sekolah yang bersifat transformasional. Kepemimpinan tersebut diharapkan dapat menstimulasi perubahan/perkembangan dan dapat memberikan iklim yang kondusif untuk tumbuh kembangnya kepemimpinan guru. Model kepemimpinan transformasional dapat beradaptasi dan menerima perubahan-perubahan yang terjadi dengan cepat didunia pendidikan sebagai dampak globalisasi dan perkembangan ilmu pengetahuan dan teknologi. Melalui kepemimpinan transformasional, diharapkan guru dapat terpacu untuk selalu mengikuti perubahan dan perkembangan pengetahuan dan metode pembelajaran.
\end{abstract}

Kata kunci: komunitas belajar, kepemimpinan transformasional, kualitas pendidikan di pedesaan, pedesaan

\section{PENDAHULUAN}

Salah satu kunci keberhasilan pembangunan di Indonesia terletak pada kapasitas ataupun kompetensi sumber daya manusia Indonesia. Masyarakat dan setiap individu yang membangun masyarakat merupakan agent of development, yang dengan segala bentuk profesinya dan posisinya dalam masyarakat dapat secara aktif berperan serta dalam pembangunan berkelanjutan. Salah satu 
bidang yang sangat susbtansial dan menjadi pilar utama pembangunan adalah pendidikan. Melalui pendidikan, suatu negara/masyarakat dapat membangun human capital yang menjadi aset utama pembangunan. Manusia dan masyarakat yang terbentuk melalui pendidikan yang berkualitas akan mampu menopang pilar pembangunan yang lainnya di berbagai sector: teknologi, komunikasi, pertanian, kelautan, transportasi, pengelolaan lingkungan dan bidang bidang yang lain. Pembangunan multisektor ini diawali dengan pembangunan kognisi, mental, karakter, serta keterampilan manusia dan masyarakat Indonesia. Keberhasilan pembangunan suatu negara selalu ditopang oleh peran serta seluruh komponen masyarakat baik didesa maupun dikota secara bersama-sama dan berkelanjutan. Dampak keberhasilan pembangunan juga seharusnya dapat dinikmati oleh seluruh elemen masyarakat, baik di perkotaan maupun pedesaan.

Daerah pedesaan seringkali menjadi daerah yang terabaikan dan tertinggal dalam pembangunan, padahal area tersebut seringkali menyimpan potensi alam yang sangat besar yang dapat menjadi natural capital untuk pembangunan. Salah satu pendekatan yang dapat dilaksanakan untuk meningkatkan sumber daya manusia pembangunan di pedesaan adalah dengan meningkatkan kapasitas ataupun kompetensi para pendidik di pedesaan. Seringkali daerah pedesaan tertinggal dalam bidang pendidikan dikarenakan beberapa faktor, diantaranya kurangnya fasilitas pendidikan, kuantitas tenaga pendidik, kualifikasi tenaga pendidik, serta seringkali masih tersebar dan dianutnya nilai yang menggangap bahwa mereka tidak perlu menempuh pendidikan tinggi tinggi karena bagaimanapun akan tetap kembali bekerja disawah atau ladang milik mereka, milik tetangga atau orang lain dan persepsi bahwa anak anak perempuan tidak perlu sekolah tinggi tinggi karena akan kembali ke dapur. Nilai-nilai tersebut merupakan salah satu sederetan contoh nilai-nilai masyarakat yang dapat menghambat pembangunan berkelanjutan.

Potensi peran penting daerah pedesaan terhadap pembangunan bangsa mengindikasikan pentingnya pendidikan dalam pembangunan pedesaan. Salah satu pendekatan yang dapat dilaksanakan adalah dengan meningkatkan kualitas dan kompetensi guru/pengajar didaerah pedesaan. Guru merupakan salah satu kunci penentu kualitas pendidikan di Indonesia. Guru yang mempunyai kompetensi yang tinggi akan mampu membawa perubahan positif di bidang pendidikan, meningkatkan kemampuan belajar siswa baik dari segi kognitif, afektif serta psikomotorik. Akan tetapi para guru tidak dapat tumbuh dan berkembang dengan sendirinya. Mereka membutuhkan faktor penunjang yang dapat memfasilitasi pendidikan guru di daerah pedesaan. Paper ini akan memfokuskan pembahasan dan analisa pada dua faktor utama, yaitu peran komunitas belajar pengembangan profesional guru (professional learning communities) dan kepemimpinan sekolah di daerah pedesaan (rural school leadership).

\section{PERMASALAHAN DAN TUJUAN}

Studi ini bertujuan:

1. Mengekplorasi peran dan dampak/kontribusi komunitas belajar guru terhadap peningkatan belajar guru di daerah pedesaan.

2. Menganalisa peran dan kontribusi kepemimpinan di sekolah terhadap peningkatan kualitas profesionalisme guru di daerah pedesaan.

\section{PEMBAHASAN}

Dua faktor substansial yang dapat menunjang pendidikan guru adalah belajar secara bersama melalui komunitas belajar dan keberadaan pemimpin sekolah/kepala sekolah yang bersifat suportif serta memotivasi guru untuk selalu belajar dan mengikuti perkembangan dan perubahan ilmu pengetahuan yang terjadi diluar lingkup sekolah, bahkan dalam skala global. Pembelajaran dalam konteks ini dianalisa melalui perspektif sosial dan budaya. Pembelajaran tidak dapat lepas dari 
lingkungan sosial dimana guru berada/mengajar dan suatu pembelajaran membutuhkan interaksi sosial dan keberadaan faktor eksternal sosial. Teori Vygotsky tentang komunitas belajar menyebutkan bahwa kebudayaan dan interaksi sosial memegang peranan yang penting dalam proses perkembangan (Bransford, Derry, dkk., 2005). Melalui teori ZPD, Vygotsky menekankan bahwa perkembangan manusia dipengaruhi oleh interaksi antara kemampuan dirinya/kompetensi diri dan pembelajaran berkolaborasi dalam dunia sosial diluar dirinya (Bransford, Derry, dkk., 2005, hal. 65). Model pemahaman pembelajaran How People Learn (HPL) mengindikasikan pentingnya peran komunitas sebagai konteks/tempat sosial individu untuk belajar dan berkembang.

Model HPL (gambar 1) menunjukkan terdapat tiga kelompok metode/pendekatan dalam belajar, baik pendekatan yang difokuskan pada pemahaman/pengetahuan tentang pembelajar, pengetahuan ataupun alat/parameter untuk mengetahui keberhasilan pembelajaran. Semua pendekatan tersebut berada dalam konteks yang sama, yaitu masyarakat/komunitas. Hal ini menunjukkan bahwa semua jenis pembelajaran bersifat sosial dan membutuhkan lingkungan sosial untuk menjadi sebuah pembelajaran/pendidikan yang efektif dan berkembang.

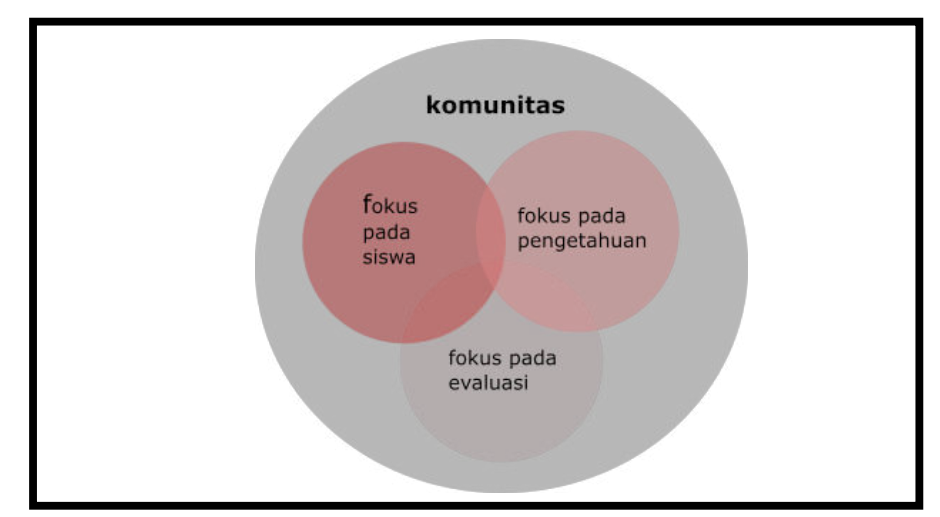

Gambar 1. Model HPL (Bransford, Darling-Hammond, dkk., 2005, hal. 32)

\subsection{Kelompok/Komunitas belajar Guru}

\subsubsection{Peran dan Implikasi Komunitas belajar Guru}

Tugas utama pengajar tidak hanya mengajar dan mendidik para siswa, akan tetapi semua pengajar juga mempunyai kewajiban untuk secara berkelanjutan memperkaya diri dengan selalu belajar. Guru mempunyai dualitas tugas yang saling terkait: mengajar dan meningkatkan kemampuan diri dengan belajar dan mengembangkan visi diri tentang apa, kapan dan bagaimana harus belajar (Darling-Hammond dan McLaughin, 1995, dikutip dalam Vescio dkk., 2006, hal. 1). Pembentukan komunitas belajar untuk guru yang mengajar di daerah pedesaan dapat berperan penting dalam memotivasi guru untuk belajar melalui peer group, sesama kolega guru dan jejaring professional guru. Disamping itu, mereka dapat saling mengisi kekurangan ataupun gap pengetahuan dan skill melalui belajar kolaborasi dan kooperatif. Pembelajaran jenis ini dapat secara potensial mengatasi masalah pendidikan yang seringkali berkembang dipedesaan, yaitu keterbatasan fasilitas dan penyebaran informasi. Suburnya budaya kolektifisme di pedesaan dapat memberikan iklim yang kondusif untuk saling belajar/belajar secara berkelompok.

Komunitas belajar guru daerah pedesaan memungkinkan para guru untuk mengetahui masalah-masalah pendidikan yang timbul dalam konteks yang sama, serta berbagi strategi ataupun problem solving yang efektif untuk mengatasi masalah yang sejenis/dalam konteks yang sama. 
Komunitas belajar didefinisikan sebagai suatu kelompok dimana beberapa individu/institusi membentuk kesatuan untuk saling bekerjasama, sharing, menghadapi perubahan, menghadapi tantangan dan resiko profesi, serta menjalankan tanggung jawab (Himmelman, 1994, hal 28, dikutip dalam Kilpatrick dkk., 2003, hal. hal 2). Komunitas belajar dibentuk berdasarkan dua asumsi utama: pengetahuan bersifat lokal dan dapat berkembang berdasarkan pengalaman sehari-hari (Buysee, Sparkman dan Wesley, 2003, dikutip dalam Vescio dkk., 2006, hal. 3) dan komunitas belajar dapat meingkatkan pengetahuan profesionalisme guru serta meningkatkan kemampuan akademik siswa (Vescio dkk., 2006, hal. 3). Beberapa karakteristik komunitas pembalajaran guru adalah terbentuknya nilai-nilai dan norma-norma bersama, sebagai contoh hal-hal yang berkaitan dengan kemampuan belajar siswa, manajemen waktu, peran orang tua, guru dan petugas administrasi dalam pendidikan (Newmann dan Associates, 1996, dikutip dalam Vescio dkk., 2006, hal. 3), memfokuskan diskusi dan kegiatan pada pengembangan metode pembelajaran untuk meningkatkan kemampuan belajar siswa (Newmann \& associates, 1996, dikutip dalam Vescio dkk., 2006, hal. 3), serta adanya dialog refleksif secara berkelanjutan (Newmann dkk. 1996, hal. 182, Vescio dkk., 2006, hal. 3).

Jauhnya atau bahkan terisolasinya daerah pedesaan dari wilayah perkotaan, yang mengindikasikan pula terbatasnya fasilitas pendidikan yang dapat sampai di pelosok pedesaan seringkali menghambat guru untuk berkembang. Mereka seringkali juga tidak dapat mengikuti seminar-seminar ataupun forum-forum ilmiah yang bertujuan untuk meng-update ilmu pengetahuan dan membahas trend isu-isu pengetahuan. Metode mengikuti forum-forum ilmiah yang diselenggarakan diarea yang jauh dari lokasi tempat mengajar guru sehingga guru tidak dapat mengikuti secara rutin, terputus-putus atau tidak berkesinambungan cenderung kurang efektif. Program-program pengembangan profesionalisme guru yang tidak berkala dan terpisah-pisah atau terfragmentasi cenderung kurang efektif (Barnett, 2002, dikutip dalam Dede dkk., 2008, hal. 9), terutama ketika guru harus menerapkan apa yang dipelajarinya dalam forum tersebut dalam dunia dan lingkungan nyata di sekolah masing masing, seringkali membuat guru-guru frustasi dan putus asa karena metode tersebut kurang efektif dan membutuhkan banyak waktu (Dede dkk., 2008, hal. 9).

Komunitas belajar guru yang didirikan secara bersama-sama dengan cara berkumpul secara rutin untuk menyelenggarakan kegiatan akademik ini seringkali diselingi acara-acara bernuansa sosial-budaya dan menjadi sarana silaturahmi. Berkembangnya komunitas belajar ini tidak dapat lepas dari konsep interaksi sosial dalam masyarakat. Komunitas belajar ini merupakan manifestasi dari konstruksi ilmu pengetahuan yang dikembangkan melalui interaksi sosial di lingkungan sosialbudaya tertentu yang mendorong anggota komunitas tersebut untuk saling berkolaborasi, menuntun dan belajar, baik dari sesama teman guru/peer ataupun dari instruktur (Vygotsky, dikutip dalam Loving dkk., 2007, hal. 179). Unsur interaksi sosial yang berdasarkan pada keseharian dan lokasi yang tidak berjauhan (terutama untuk non-online learning communities) dapat meminimalisasi tantangan kurangnya motivasi guru untuk mengikuti program pengembangan kemampuan profesionalisme. Beberapa tantangan yang dihadapi guru dalam pengembangan kemampuan profesionalismenya meliputi: keengganan guru untuk meninggalkan/keluar dari kelas dan meninggalkan keluarganya, jarak yang jauh menyebabkan guru harus bepergian dan membutuhkan waktu yang lama serta workshop/seminar yang diikuti kurang relevan atau tidak berkontribusi banyak dalam membantu mereka menyelesaikan tugas-tugas mengajarnya (Harmon dkk., 2007, hal. 9).

Disamping mengatasi kekurangan/kelemahan pengembangan profesionalisme guru melalui forum-forum ilmiah yang terfragmentasi, komunitas belajar guru memungkinkan guru untuk belajar dari pengalaman secara kolaboratif, dalam suasana yang demokratis/kolegial serta melakukan refleksi bersama (Kelly dan Cherkowski, 2015). Keefektifan suatu kegiatan pengembangan kemampuan profesionalisme guru ditandai dengan beberapa hal: bentuk kegiatan yang lebih lama, mempunyai konten yang lebih dalam dan melibatkan pembelajaran secara aktif, kegiatan yang mempunyai durasi waktu lebih lama dan melibatkan pengalaman guru, jenis kegiatan yang 
melibatkan partisipasi aktif guru, menekankan pada pendalaman konten dan teknik mengajar, memotivasi guru untuk diskusi, merencanakan dan mempraktekkan pengetahuan yang telah didapatkannya, kegiatan yang bersifat terstruktur dan saling terkait (Birman dkk., 2000). Disamping memberikan kontribusi positif dibidang pengembangan kognisi, konten dan pengetahuan, komunitas belajar juga memberikan manfaat dibidang mentalitas ataupun nilai pembelajaran. Shared expertise yang dibentuk dari komunitas belajar berpotensi untuk menumbuhkan jiwa saling membutuhkan (Kelly dan Cherkowski, 2015, hal. 5). Kolektifitas yang terbentuk secara bersama-sama dapat mempererat kesatuan dalam kelompok karena pengetahuan yang terbentuk bersifat horizontal, tidak terstruktur secara vertikal (Sergiovanni, 1994, dikutip Kelly dan Cherkowski, 2015, hal. 5). Metode berbagi pengetahuan dalam bentuk komunitas belajar dapat membuat guru merasa aman/nyaman belajar bersama-sama karena mereka tidak akan merasa tertekan untuk berhasil secara sempurna, guru/anggota komunitas belajar dapat mengutarakan dan mendiskusikan pengalaman belajarnya ataupun menyuarakan masalah-masalah/kendala-kendala yang dihadapinya selama belajar/mengajar (Hargreaves dan Fullan, 2012, hal 114, dikutip dalam Kelly dan Cherkowski, 2015, hal. 5). Komunitas akademik tersebut sangat berpotensi dalam meningkatkan pedagogi otentik guru dan meningkatkan kemampuan guru dalam berinteraksi dan belajar dalam konteks sosial, serta berdampak pada tata kelola dan reformasi sekolah (Louis dan Marks, 1996, hal. 26).

\subsubsection{Karakteristik, Iklim Tumbuh Kembang dan Keberlanjutan Komunitas Belajar}

Peran pimpinan dalam sebuah organisasi sangat vital. Seorang pemimpin dapat menciptakan dan mengubah budaya ataupun iklim kerja di lingkungannya (Nawab, 2011). Terbentuknya komunitas belajar juga ditunjang/difasilitasi oleh beberapa elemen, diantaranya adalah kepemimpinan, tim/group yang mampu belajar dari pengalaman, reflektif, serta kegiatan/aktifitas kelompok yang bersifat terstruktur (Reichstetter, 2006). Komunitas belajar ini ditandai dengan beberapa karakteristik umum.

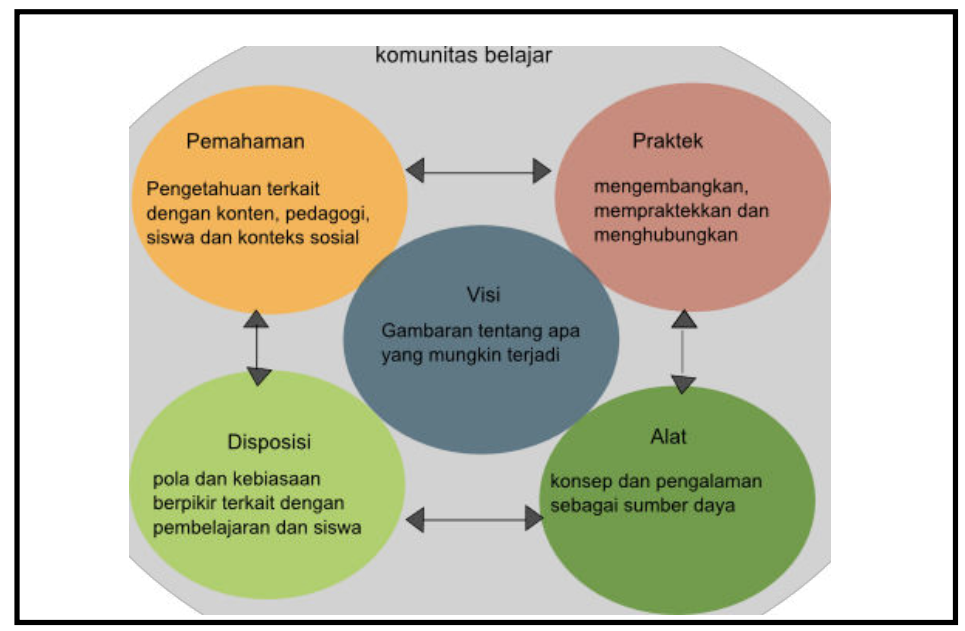

Gambar 2. Model pembelajaran dalam komunitas (Hammerness dkk., 2005)

Tiga karakteristik kunci komunitas belajar yang efektif adalah: materi/konten yang mendalam, serta berorientasi pada memberikan kesempatan pada guru untuk mempraktekkan apa yang dipelajari, memberikan kesempatan kepada guru untuk mempraktekkannya didalam kelas dalam konteks yang authentic, serta tersedianya fasilitas dan dorongan dari pemimpin ataupun instruktur belajar (Jeanpierre dkk., 2005, hal. 682-684). Agar bertahan dan berlanjut, komunitas 
belajar memerlukan beberapa unsur, diantaranya adalah lingkungan kolaboratif, terdapatnya nilainilai kepercayaan dan saling menghargai (Kelly dan Cherkowski, 2015).

Sebuah komunitas belajar yang efektif ditandai dengan beberapa karakteristik, diantaranya adalah mempunyai visi dan nilai-nilai bersama, tanggung jawab bersama terhadap pembelajaran siswa, terbentuknya kolaborasi yang difokuskan pada pembelajaran, terselenggaranya pembelajaran yang bersifat individu dan kolektif, rekfleksi, keterbukaan, jejaring dan kemitraan, keanggotaan yang bersifat inklusif, kepercayaan, saling menghargai dan menyemangati (Bolam dkk., 2005). Komunitas belajar ini dapat terbentuk, terorganisasi dan bertahan/berkelanjutan apabila memenuhi empat proses utama, yaitu: mengoptimalkan sumber daya, meningkatkan pembelajaran individu dan kolektif, sosialisasi/promosi pengenalan komunitas serta kepemimpinan dan manajemen yang efektif (Bolam dkk., 2005). Prenger, Poortman dan Handelzalts (n.d.) mengidentifikasi beberapa ciri/karakter komunitas yang efektif, yaitu kesamaan fokus untuk mencapai tujuan/hasil yang nyata, terdapatnya fokus bersama/kolektif pada hasil pembelajaran siswa, dialog reflektif, kolaborasi dan partisipasi aktif, kepemimpinan, praktek pembelajaran, saling mempercayai, fasilitas, dukungan dari stakeholder, pengetahuan dan motivasi anggota komunitas.

\subsection{Kepimpinan Transformasional dan Guru Sebagai Pemimpin}

Salah satu elemen yang penting untuk memfasilitasi komunitas belajar guru adalah kepemimpinan di sekolah. Beberapa kondisi sekolah di area pedesaan yang dapat menimbulkan tantangan untuk pemimpin sekolah di pedesaan, diantaranya faktor kondisi geografis/jarak, isolasi budaya, keterbatasan dana/financial, keterbatasan jumlah penduduk, isolasi personal serta stabilitas sejarah (Hood dan Clarke, 2002, dikutip dalam Ashton dan Duncan, n.d.). Hobson et al. (2003, dikutip dalam Ashton dan Duncan, n.d.) mengidentifikasi beberapa kendala umum yang dihadapi oleh kepala sekolah, yaitu isu-isu terkait dengan otoritas, gaya kepemimpinan, serta pengaruh pimpinan sebelumnya, perasaan terisolasi, manajemen tugas, waktu dan prioritas, manajemen anggaran keuangan sekolah, kendala berkaitan dengan staff/pegawai, pelaksanaan program-program sekolah dari pemerintah serta isu terkait dengan bangunan sekolah dan manajemen tempat. Oleh karena itu, untuk mengatasi kendala-kendala tersebut, kepemimpinan sekolah yang efektif sangat dibutuhkan untuk meningkatkan kualitas/perkembangan dan perubahan di sekolah (Halverson, 2005). Beberapa riset menemukan bahwa kepemimpinan transformasional sangat konteksual dan efektif untuk organisasi sekolah (Chance dan Segura, 2009; Masumoto dan Brown-Welty, 2009).

\subsubsection{Kepemimpinan Transformasional}

Kepemimpinan transformasional lebih menitikberatkan pada fasilitasi perubahan (Masumoto dan Brown-Welty, 2009, hal. 3). Kepemimpinan transformasional berbasis pada kemampuan pimpinan untuk melakukan perubahan dibandingkan dengan lebih menekankan karakter individu pimpinan ataupun hubungan antara pimpinan dan yang dipimpin (Lussier dan Achua, 2004, hal. 355). Kepemimpinan transformasional berkaitan dengan aktivitas pimpinan untuk melakukan perubahan/perkembangan dengan mengkomunikasikan isu-isu yang sedang berkembang dan membentuk visi untuk berkembang (Lussier dan Achua, 2004, hal. 356). Pemimpin transformasional ditandai dengan beberapa karakter, yaitu melihat dirinya sebagai agen perubahan, seorang yang visionaris dan mempunyai keyakinan pada kemampuan intusinya, penganbil resiko, memiliki kemampuan untuk menyampaikan nilai-nilai utama organisasi, memiliki kognisi yang tinggi, mempercayai orang-orang yang dipimpinnya dan memiliki kepekaan terhadap kebutuhan mereka, serta bersifat fleksibel dan terbuka terhadap pembelajaran dari pengalaman baru (Lussier dan Achua, 2004, hal. 357-358). Pemimpin transformasional memimpin organisasi yang dipimpinnya melalui beberapa proses transformasi/perubahan, yaitu menanamkan pemahaman komunitas yang 
dipimpinnya akan pentingnya melakukan perubahan, membentuk visi bersama, memimpin dalam masa transisi serta mengimplementasikan perubahan (Lussier dan Achua, 2004, hal. 361).

\begin{tabular}{|l|l|}
\hline \multicolumn{1}{|c|}{ Komponen Tingkah laku } & \multicolumn{1}{c|}{ Deskripsi } \\
\hline Pembentukan dan artikulasi visi & $\begin{array}{l}\text { Pemimpin transformasional selalu aktif mencari } \\
\text { peluang untuk organisasinya, menyusun and } \\
\text { mengartikulasikan visi, serta mendorong } \\
\text { anggotanya untuk menjadi lebih berkualitas }\end{array}$ \\
\hline Role model & $\begin{array}{l}\text { Memberikan contoh yang konsisten dengan nilai } \\
\text { dan tujuan/goal organisasi }\end{array}$ \\
\hline Orientasi pada kelompok & $\begin{array}{l}\text { Membangun kelompok dan komitmen kelompok } \\
\text { untuk mencapai tujuan bersama }\end{array}$ \\
\hline $\begin{array}{l}\text { Goal untuk mendapatkan capaian } \\
\text { yang tinggi }\end{array}$ & $\begin{array}{l}\text { Pemimpin mempunyai harapan tinggi terhadap } \\
\text { kinerja anggotanya }\end{array}$ \\
\hline $\begin{array}{l}\text { Hubungan pimpinan dan yang } \\
\text { dipimpin }\end{array}$ & $\begin{array}{l}\text { Mempercayai, menghargai, dan menyemangati } \\
\text { anggotanya, baik dalam skala individual ataupun } \\
\text { organisasi }\end{array}$ \\
\hline Pemberdayaan & $\begin{array}{l}\text { Pemimpin transformasional mendorong } \\
\text { anggotanya untuk berpikir out of the box dan } \\
\text { menganalisa kembali paradigm-paradigma lama }\end{array}$ \\
\hline
\end{tabular}

Gambar 3. Karakteristik kepemimpinan transformasional (Lussier dan Achua, 2004, hal. 358)

Kepemimpinan transformasional tidak hanya berefek pada terjadinya perubahan, akan tetapi juga berdampak pada faktor-faktor yang lain. Kepemimpinan transformasional dapat meningkatkan kepercayaan diri dan motivasi pembelajaran guru (Hipp, 1997). Pemimpin transformasional dapat meningkatkan rasa percaya diri guru melalui beberapa cara: mempercayai kemampuan guru, menginspirasi serta mendorong kinerja tim, menghargai kinerja dan usaha guru, memberikan dorongan individu dan kelompok, mampu menangani isu-isu terkait manajemen sikap siswa, mendorong tumbuhnya rasa kebersamaan (Hipp, 1997, hal. 9).

\subsubsection{Guru sebagai Pemimpin dan Budaya Kooperatif}

Dorongan dan kepercayaan pimpinan/kepala sekolah transformasional sangat signifikan untuk peningkatan kemampuan guru. Guru diharapkan untuk tidak hanya kompeten dikelas akan tetapi dapat menjadi pimpinan. Kepemimpinan guru didefinisikan sebagai suatu proses dimana guru, baik secara individu ataupun bekelompok, bersama-sama saling memotivasi satu sama lain (memotivasi guru yang lain, kepala sekolah dan komunitas sekolah yang lain) untuk meningkatkan kualitas belajar agar prestasi/kemampuan belajar siswa meningkat (York-Barr dan Duke, dikutip dalam Charteris dan Smardon, 2014, hal. 109). Disamping itu guru juga mempunyai kapasitas untuk membentuk iklim dan budaya yang positif disekolahnya (Roby, n.d.). Guru dapat memimpin perubahan di sekolah melalui berbagai cara: membantu teman teman guru yang lain untuk belajar, membina iklim kebersamaan, mengkritisi isu-isu di sekolah dan merekomendasikan solusinya, membentuk komunitas belajar, mengadakan kegiatan mentoring, bersikap reactive dan proactive, mengambil bagian dalam keputusan serta mengembangkan kemampuan professional baik secara individu ataupun secara bersama-sama (Roby, n.d., hal. 788). Kepemimpinan guru akan sangat berkembang di dalam sekolah yang mempunyai iklim distribusi kekuasaan dan otoritas, dimana kepala sekolah mempercayai anggota sekolah untuk memimpin kegiatan-kegiatan sekolah (Muijs dan Harris, 2006, hal. 2). Tumbuhnya kepemimpinan guru harus didukung oleh budaya sekolah yang kooperatif, supportif, desentralisasi kekuasaan, dan mempunyai persepsi yang positif terhadap 
keterlibatan individu dalam kegiatan komunitas belajar (Blase, 1991, dikutip dalam Kelley, 2011, hal. $3)$.

Kepala sekolah menjadi kunci dari keberhasilan kepemimpinan guru. Kepala sekolah dapat membentuk kapasitas kepemimpinan guru melalui dua proses: menumbuhkan budaya jujur, mempercayai dan profesionalisme, serta membuka/memberikan kesempatan untuk guru sesuai dengan peran dan keahliannya (Habegger, 2008). Budaya organisasi dibentuk oleh pimpinan, melalui tiga tingkatan: tingkat yang pertama adalah asumsi dasar yang kemudian diwujudkan dalam nilai nilai organisasi dan wujud fisik/tangible yang berupa artifak organisasi (Schein, 2004, hal. 26).

Dibalik terbentuk dan berkembangnya kepemimpinan guru, terdapat pemimpin/kepala sekolah yang berkarakter transformasional yang dapat mendukung/mendorong dan memfasilitasi iklim yang kondusif, serta menciptakan budaya sekolah yang kooperatif. Budaya kooperatif ini berpotensi menjadi akar tumbuhnya komunitas belajar guru.

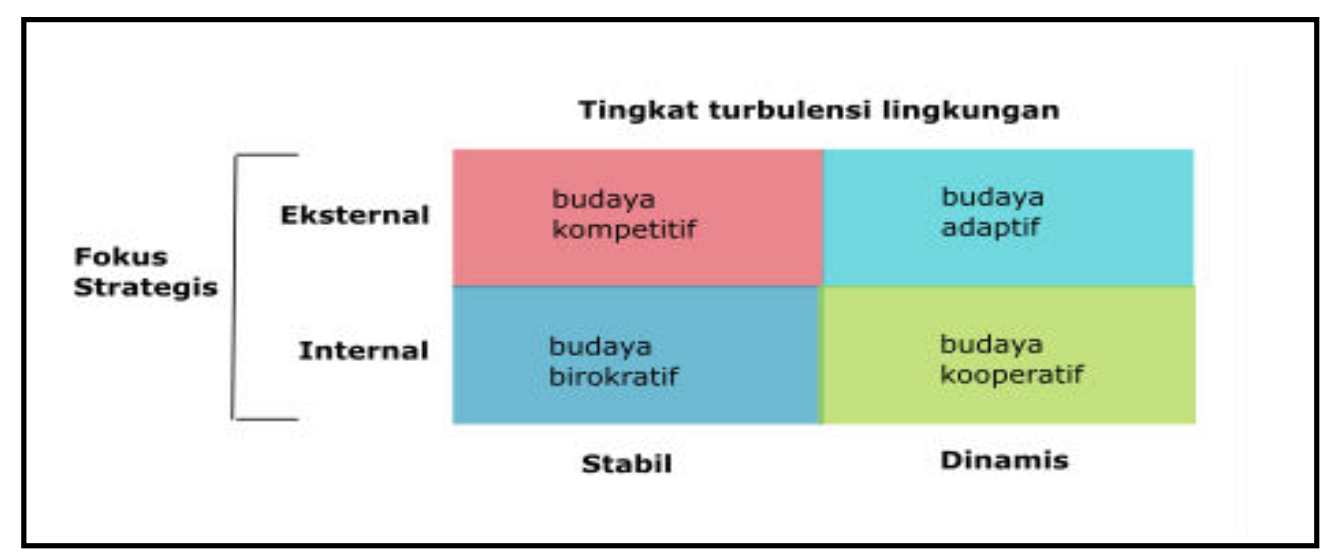

Gambar 4. Jenis budaya organisasi (Lussier dan Achua, 2004, hal. 424)

Budaya kooperatif sekolah sangat kondusif untuk perkembangan komunitas belajar guru. Dalam budaya kooperatif, fokus organisasi secara internal diarahkan pada pemberdayaan anggota organisasi agar responsif terhadap perubahan yang terjadi di luar organisasi (Lussier dan Achua, 2004, hal. 424). Budaya kooperatif sekolah, visi serta gaya kepemimpinan transformasional berpotensi sebagai fasilitasi vital pemberdayaan guru di pedesaan.

Tingginya minat penduduk Indonesia untuk menjadi guru dapat menjadi modal/aset penting pembangunan. Sebagai contoh dari 305.956 mahasiswa yang terdaftar di Universitas Tebuka Indonesia, tahun akademik 2015-2016, terdapat sekitar 225.716 yang tertarik menjadi guru (Mukminin dkk., n.d., hal. 309). Pemberdayaan guru di area pedesaan tidaklah cukup hanya dengan memberikan pelatihan-pelatihan formal, akan tetapi juga perlu ditunjang dengan komunitas sharing guru. Guru-guru perlu mendapat pengalaman melalui sharing yang diberikan oleh guru guru model yang telah mempunyai pengetahuan lebih (Wahyudi dan Treagust, 2004, hal. 470). Dengan demikian diharapkan banyak guru berkualitas akan berkembang di Indonesia dan bersama sama dapat meningkatkan mutu pendidikan di Indonesia.

\section{KESIMPULAN}

Salah satu upaya pembangunan di daerah pedesaan adalah melalui peningkatan kualitas pendidikan. Peningkatan ini dapat dilaksanakan melalui pemberdayaan guru di pedesaan. Pemberdayaan ini dapat ditempuh dengan cara membentuk dan mengembangkan komunitas belajar 
guru. Di dalam komunitas ini berpotensi berkembang rasa kebersamaan, saling memotivasi sesama guru dalam belajar untuk meingkatkan kemampuannya yang pada akhirnya diharapkan dapat meningkatkan kualitas pendidikan dan prestasi siswa di sekolah. Sharing pengetahuan yang berlangsung cenderung bersifat horizontal sehingga tidak menimbulkan kesan memaksa atau menekan pada guru. Cara yang kedua adalah melalui pembentukan karakter kepemimpinan transformasional baik di tingkat kepala sekolah ataupun kepemimpinan guru. Kepemimpinan dan kemampuan kepala sekolah dalam menciptakan iklim kebersamaan dan saling percaya menjadi dasar terbentuknya komunitas belajar guru.

\section{DAFTAR PUSTAKA}

Ashton, B., dan Duncan, H. E. (n.d.): A Beginning Rural Principal's Toolkit: A Guide for Success.

Birman, B. F., Desimone, L., Porter, A., dan Garet, M. S. (2000): Designing Professional Development that Works, Educational Leadership.

Bolam, R., McMahon, A., Stoll, L., Thomas, S., Wallace, M., Greenwood, A., Hawkey, K., Ingram, M., Atkinson, A., dan Smith, M. (2005): Creating and Sustaining Effective Professional Learning Communities, 1-158.

Bransford, J., Darling-Hammond, L., dan LePage, P. (2005): Introduction, 1-39 dalam L. DarlingHammond dan J. Bransford, ed., Preparing Teachers for A Changing World. What Teachers should Learn and be able to do, John Wiley \& Sons, Inc., San Fransisco.

Bransford, J., Derry, S., Berliner, D., Hammerness, K., dan Beckett, K. L. (2005): Theories of learning and their roles in teaching, 40-87 dalam L. Darling-Hammond dan J. Bransford, ed., Preparing Teachers for A Changing World. What Teachers should Learn and be able to do, John Wiley \& Sons, Inc., SanFransisco.

Chance, P. L., dan Segura, S. N. (2009): A Rural High School's Collaborative Approach to School Improvement, Journal of Research in Rural Education, 24(5), 1-12.

Charteris, J., dan Smardon, D. (2014): Dialogic peer coaching as teacher leadership for professional inquiry, International Journal of Mentoring and Coaching in Education, 3(2), 108-124.

Dede, C., Ketelhut, D. J., Whitehouse, P., Breit, L., dan McCloskey, E. M. (2008): A Research Agenda for Online Teacher Professional Development, Journal of Teacher Education, 60(8), 8-19. https://doi.org/10.1177/0022487108327554

Habegger, S. (2008): The Principal's Role in Successful Schools: Creating a Positive School Culture, Principal.

Halverson, R. (2005): A Distributed Leadership Perspective on how Leaders use Artifacts to Create Professional Community in Schools, Annual Conference of the University Council of Educational Administration, Nashville, TN.

Hammerness, K., Darling-Hammond, L., Bransford, J., Berliner, D., Cochran-Smith, M., McDonald, M., dan ZeichnerKenneth (2005): How teachers learn and develop dalam L. Darling-Hammond dan J. Bransford, ed., Preparing Teachers for A Changing World. What Teachers should Learn and be 
able to do, John Wiley \& Sons, Inc., San Fransisco.

Harmon, H. L., Gordanier, J., Henry, L., dan George, A. (2007): Changing Teaching Practices in Rural Schools, The Rural Educator, 28(2), 8-12.

Hipp, K. A. (1997): Documenting the Effects of Transformational Leadership Behavior on Teacher Efficacy., Paper presented at the Annual Meeting of the American Educational Research Association (Chicago, IL, March 24-28, 1997).

Jeanpierre, B., Oberhauser, K., dan Freeman, C. (2005): Characteristics of Professional Development That Effect Change in Secondary Science Teachers' Classroom Practices, Journal of Research in Science Teaching, 42(6), 668-690.

Kelley, J. y D. . (2011): Teacher's and Teacher Leaders' Perceptions of the Formal Role of Teacher Leadership, Georgia State University, diperoleh melalui situs internet: http://scholarworks.gsu.edu/eps_diss/70.

Kelly, J., dan Cherkowski, S. (2015): Collaboration, Collegiality, and Collective Reflection: A Case Study of Professional Development for Teachers, Canadian Journal of Educational Administration and Policy, (169), 1-27.

Kilpatrick, S., Barrett, M., dan Jones, T. (2003): Defining Learning Communities.

Louis, K. S., dan Marks, H. (1996): Does Professional Community Affect the Classroom? Teachers' Work and Student Experiences in Restructuring Schools.

Loving, C. C., Schroeder, C., Kang, R., Shimek, C., dan Herbert, B. (2007): Blogs: Enhancing Links in a Professional Learning Community of Science and Mathematics Teachers, Contemporary Issues in Technology and Teacher Education, 7(3), 178-198.

Lussier, R. N., dan Achua, C. F. (2004): Leadership. Theory, Application, Skill Development (2nd ed.), South-Western, United States of America.

Masumoto, M., dan Brown-Welty, S. (2009): Case Study of Leadership Practices and SchoolCommunity Interrelationships in High-Performing, High-Poverty, Rural California High Schools, Journal of Research in Rural Education, 24(1), 1-18.

Muijs, D., dan Harris, A. (2006): Teacher led school improvement: Teacher leadership in the UK, Teaching and Teacher Education.

Mukminin, A., Kamil, D., Muazza, M., dan Haryanto, E. (n.d.): Why Teacher Education? Documenting Undocumented Female Student T eachers' Motives in Indonesia: A Case Study.

Nawab, A. (2011): Exploring leadership practices in rural context of a developing country, International Journal of Academic Research in Business and Social Sciences, 1(3), 181-189.

Prenger, R., Poortman, C. L., dan Handelzalts, A. (n.d.): Factors influencing teachers' professional development in networked professional learning communities, Teaching and Teacher 
Education, 68, 77-90.

Reichstetter, R. (2006): Defining a Professional Learning Community.

Roby, D. (n.d.): Teacher Leaders Impacting School Culture.

Schein, E. H. (2004): Organizational Culture and Leadership (3rd ed.), John Wiley \& Sons, Inc., San Fransisco.

Vescio, V., Ross, D., dan Adams, a (2006): A review of research on professional learning communities: What do we know, National School Reform Faculty Research Forum, diperoleh melalui situs internet:

http://scholar.google.com/scholar?hl=en\&btnG=Search\&q=intitle:A+review+of+research+on+p rofessional+learning+communities:+What+do+we+know?\#2, 1-37.

Wahyudi, W., dan Treagust, D. F. (2004): An Investigation of Science Teaching Practices in Indonesian Rural Secondary Schools, Research in Science Education, 34, 455-474. 